\title{
KNOWLEDGE, ATTITUDE AND PRACTICE TOWARDS SALT INTAKE OF ITS ASSOCIATED FACTORS AMONG HYPERTENSIVE FELDA RESIDENCE IN TERENGGANU
}

\author{
WAN AIN NADIRAH CHE WAN MANSOR, SAKINAH HARITH*, \\ CHE SUHAILI CHE TAHA and YING QIAN ONG \\ School of Nutrition and Dietetic, Faculty of Health Sciences, Universiti Sultan Zainal Abidin, \\ Gong Badak Campus, 21300 Kuala Nerus, Terengganu, Malaysia \\ *E-mail: sakinahharith@unisza.edu.my
}

Accepted 13 October 2021, Published online 30 November 2021

\begin{abstract}
Hypertension in Malaysia, where at least one out of three Malaysian adults has hypertension, is a significant contributor to cardiovascular diseases. Therefore, this cross-sectional study focus to determine the prevalence of hypertension and the association of socio-demographic, anthropometry status, blood pressure, and Knowledge, Attitude, and Practice (KAP) towards salt intake with hypertension among participants in FELDA's residence in Terengganu, Malaysia. About 94 participants from three FELDA's in Terengganu participated in this study. The data were analyzed by SPSS. The prevalence of hypertension in this study was $39.4 \%$. The majority of participants were females $(60.6 \%)$ with a mean age of 50.3 (12.0) years old. The KAP questionnaire is given to hypertensive participants. All participants had good knowledge of salt intake. Meanwhile, the majority of the participants in the hypertensive group (70.3\%) had a good attitude towards the salt intake. For the practice questions, $56.8 \%$ were categorized as lack of practice. The analysis revealed variables that significant with hypertension were aged $(p=0.001)$, body mass index (BMI) $(p=0.001)$, and waist circumference $(p=0.001)$. There is also a significant association between diastolic blood pressure with gender $(p=0.003)$. This evidence would be useful for an intervention program aimed at improving awareness, thereby reducing the incidence of hypertension among the FELDA communities.
\end{abstract}

Key words: Attitude, hypertension, knowledge, practice, prevalence, rural area, salt intake

\section{INTRODUCTION}

Hypertension remains a significant public health challenge in the world because it increases the risk of cardiovascular diseases (CVD), where CVD is the number one cause of death globally (World Health Organisation, 2018). In 2016, over 17.9 million people died from CVD which accounted for $31 \%$ of all global deaths (WHO, 2018). The WHO projected that by 2025 , at least 1.56 billion people, which accounted for $29.2 \%$ of the world's population would have hypertension (WHO, 2002). Not excluded, Malaysia also experienced an upsurge in CVD morbidity and mortality where at least one out of three Malaysian adults suffered from hypertension (National Health Morbidity Survey, 2015). According to Abdul-Razak et al. (2016), the prevalence of hypertension in rural

\footnotetext{
* To whom correspondence should be addressed.
}

areas was higher than in urban areas at $51.2 \%$ and $44.9 \%$, respectively. Federal Land Development Authority or commonly known as FELDA is one of the rural areas in Malaysia where all of the residences there, work as a farmer. It is a plantation area that was established in 1956 aimed to eradicate poverty through the cultivation of oil palm and rubber (Federal Land Development Authority, 2019). As we know, both rural and urban regions have different dietary patterns, socioeconomic status, and health facilities (Azahari et al., 2013; Shahar et al., 2019). Since the prevalence was higher in rural areas, therefore FELDA had been choose as a setting for this study since it was a rural area and one of the biggest parts of the countryside in Malaysia.

Sodium acts as a vital source of minerals in our body, however, overconsumption of sodium will lead to hypertension (Martin et al., 2012). Excess dietary sodium intake is not only a key determinant for CVD 
risk, but it is also associated with kidney disease, stomach cancer, osteoporosis, and obesity (Institute for Public Health, 2014). Globally, 1.7 million annual CVD deaths were caused by excess sodium intake (WHO, 2010). As stated by the WHO, the recommendation of daily sodium intake is not more than $2000 \mathrm{mg}$ or equal to $5 \mathrm{~g}$ / one teaspoon of salt (WHO, 2012). Almost all of the population in the world exceeded this recommendation (BibbinsDomingo et al., 2010; Chen et al., 2013; Eyles et al., 2014). Furthermore, sodium intake among the Malaysian healthcare staff showed that the intake exceeded the daily recommendation of sodium by 1.7 times higher than the $2000 \mathrm{mg}$ of sodium daily (Mahat et al., 2017). Besides, the states of Terengganu were among the top three highest consumption of salt in Malaysia with soya sauce being the most popular seasoning consumed that contributed to high sodium intake (Rashidah et al., 2014).

Numerous factors could affect the intake of salt among the population as well as knowledge towards the right amount of salt intake. Identification of dietary salt along with the understanding level of information, attitude, and practice towards salt intake is crucial in reducing salt consumption. A systematic review showed that a person who believed they were consuming the right amount of sodium consumed sodium higher than the WHO's recommendation (Bhana et al., 2018). All of the studies in the review showed most adults were aware that they should take $2000 \mathrm{mg}$ of sodium per day. However, they did not realize that they were consuming sodium more than the recommendation. The reason was they were unable to recognize the source of sodium in their food intake. Knowledge is the key in creating awareness for the community, not only for hypertension patients but also for the whole community because there was a positive association between nutrition knowledge and dietary intake (Spronk et al., 2019).

The attitude and practice towards salt intake are most likely influenced by the socio-demographic factors where individuals with lower-income households had higher salt intake (Grimes et al., 2010). Similarly in Malaysia, a study also showed that there was a higher sodium intake in a group with low socio-economic status (Shahar et al., 2019). Thus, going to the FELDA areas in Malaysia which are considered as rural areas will enable us to determine the association of socio-demographic factors, anthropometry status, blood pressure, and Knowledge, Attitude, and Practice (KAP) towards salt intake with hypertension among the adults' residence.

\section{MATERIALS AND METHODS}

\section{Sampling size and subjects}

This research was a cross-sectional study carried out in three plantation areas (FELDA) in Terengganu, Peninsular Malaysia which consisted of FELDA Belara, Kuala Terengganu, FELDA Selasih, Besut, and FELDA Neram 2, Kemaman. The study was performed among 94 adults aged 19 to 64 years old. The sample size for this study was calculated using Power and Sample Size (PS) Software version 3.1.2. In this software, Multiple Linear Regression (MLR) is used to calculate the sample size. Standard Deviation (SD) and Coefficient Regression ( $\beta$ ) of the anthropometry status of the previous study was used (Wellman et al., 2016). Thus, the minimum sample size required was 177 participants. The study was approved by Universiti Sultan Zainal Abidin Human Research Ethics Committee (UHREC) [UniSZA/UHREC/2019/122]. Data collection was carried out in February, September, and October 2020. The gap period in data collection was due to Restriction Movement Control Order because of the COVID19.

Participants were provided with a study information sheet and consent form before data collection. This study was divided into two-phase wherein phase I (Screening phase), all of the participants were included to determine the prevalence of hypertension among adults in FELDA residence in Terengganu. Afterward, in phase II (Study phase) only hypertension participants were included, suitable for the second objective of this study. Participants with a history of hypertension and on hypertensive treatment (taking any hypertension medication) were classified as hypertension participants. The list of FELDA's residents was obtained from FELDA's manager in each FELDA area. A simple random sampling method was used in phase I while the purposive sampling method was used for phase II. During the data collection, face to face interview method had been used in both phases.

\section{Socio-demographic information}

We collected socio-demographic information from the participants using a validated questionnaire adapted from Institute for Public Health. The questionnaire forms for normal participants and hypertensive participants were different. For the hypertensive participants, we added educational level, household income, smoking status, taking antihypertension medication, and practice a low salt diet in their questionnaires. All questionnaires were in the Malay language. 


\section{KAP on salt intake}

The KAP towards salt intake was determined by using a validated KAP questionnaire adapted from the Institute for Public Health (2014) that consisted of eight questions. Knowledge was assessed using two questions. First, do they know that high salt intake can cause serious health problems, and does a high salt diet can cause hypertension? The choices of answers were yes and no. 'Yes' will indicate score one while 'no' will indicate score zero. For attitudes, two questions on how much salt they consume with the answer scale of "too much, just the right amount, and too little". If they answer 'too much' will score zero, 'just the right amount' will score one, and 'too little' will score two. Next question was, how important to you is lowering salt in your diet with the answer scale of "not important, somewhat important, and very important". If they answer 'not important' will score zero, 'somewhat important' will score one, and 'very important' will score two. For practices questions, four questions were asked; do they add salt to food at the table and during cooking with the answer scale of "never, rarely, sometimes, often, and always". The answer 'never' will score two, 'rarely' and 'sometimes' will score one and the answer of 'often' and 'always' will score zero. Another question on do they take any action to control salt intake, the choices of answers were 'yes' and 'no'. If the answer is 'yes, the further question on what types of activities will be asked. 'yes' will score one while 'no' will score zero and each action will score one.

\section{Anthropometry measurement}

The anthropometric data were assessed in terms of body mass index (BMI), waist to hip ratio (WHR), and waist circumference. All of the anthropometric measurements were completely performed according to standard protocols (Institute for Public Health, 2014). BMI was calculated by weight ( $\mathrm{kg}$ ) and divided by the square of height $\left(\mathrm{m}^{2}\right)$. BMI was categorized by using the Asian cut-off point as normal (18.5-22.9 $\left.\mathrm{kg} / \mathrm{m}^{2}\right)$, overweight $\left(23-24.9 \mathrm{~kg} / \mathrm{m}^{2}\right)$, obese I (25-29.9 $\left.\mathrm{kg} / \mathrm{m}^{2}\right)$, and obese II $\left(\geq 30 \mathrm{~kg} / \mathrm{m}^{2}\right)$. The body weight was measured on an electronic weighing scale potable TANITA BC541 (TANITA, Japan). Height was measured using SECA Model 217 (SECA, Germany). Meanwhile, for waist circumference and hip circumference, both were measured using a SECA measuring tape (SECA, Germany). All of the measurements were taken twice and the average was recorded and used for data analysis. WHR was divided into two categories, which were $>0.90$ for males and $>0.85$ for females. Meanwhile, WC individuals were at risk if their measurements were $\geq 90 \mathrm{~cm}$ for males and $\geq 80 \mathrm{~cm}$ for females.

\section{Blood pressure reading}

The current blood pressure was taken by using a digital automatic blood pressure monitor (Omron HEM-7203) and based on the Clinical Practice Guideline of Hypertension, the blood pressure readings were taken twice. Current high blood pressure reading was defined when systolic blood pressure $(\mathrm{SBP}) \geq 140 \mathrm{mmHg}$ and/or diastolic blood pressure $(\mathrm{DBP}) \geq 90 \mathrm{mmHg}$.

\section{Data analysis}

The data were analyzed by using the Statistical Package of Social Sciences (SPSS) for Windows, version 22.0 (IBM Corp., Armonk, NY, USA). Descriptive statistics were performed to determine the characteristics of the participants in this study where presented in form of frequency and percentage. A chi-square test was conducted to determine the association between the variables involved. $P$-values that were less than 0.05 were considered significant.

\section{RESULTS}

Table 1 shows the socio-demographic characteristics of the 94 participants. The prevalence of hypertension in this study was $39.4 \%$. All of them were Malays with the majority of the participants were females $(60.6 \%)$ and married $(87.2 \%)$. The mean age of the participants was 50.3 (12.0) years. FELDA Belara had the highest number of participants which was 36 people. Both FELDA Selasih and FELDA Neram 2 had the same number of participants, which were 29. The participants were divided into nonhypertensive and hypertensive groups. In the nonhypertensive group, FELDA Belara had $45.6 \%$ of participants, followed by FELDA Selasih and FELDA Neram 2 with $28.1 \%$ and $26.3 \%$, respectively. Meanwhile, FELDA Neram 2 had $37.8 \%$ of participants in the hypertensive group, followed by FELDA Selasih and FELDA Belara with 35.2\% and $27 \%$, respectively. More than half of the hypertensive group $(70.3 \%)$ were females and married $(83.8 \%)$. The hypertensive group showed a higher number of participants $(56.8 \%)$ in the age group, between 41 to 50 years old. There was a significant association between age and hypertension among the non-hypertensive and hypertensive groups. Hypertensive participants mostly received education up to the secondary level $(64.8 \%)$ with a household income of more than RM1,000 (67.6\%). Only 10.8\% of the participants were smokers. The participants who were diagnosed with hypertension were most likely on anti-hypertension medications (56.8\%) and practiced a low salt diet $(59.5 \%)$. 
Table 1. Socio-demographic characteristics $(n=94)$

\begin{tabular}{|c|c|c|c|c|c|}
\hline Variables & $\begin{array}{l}\text { Total } \\
n=94 \\
(n, \%)\end{array}$ & $\begin{array}{c}\text { Non-hypertensive } \\
n=57 \\
(n, \%)\end{array}$ & $\begin{array}{c}\text { Hypertensive } \\
n=37 \\
(n, \%)\end{array}$ & Mean $( \pm S D)$ & $P$-value \\
\hline \multicolumn{6}{|l|}{ Location } \\
\hline FELDA Belara & $36(38.2)$ & $26(45.6)$ & $10(27.0)$ & & \\
\hline FELDA Selasih & $29(30.9)$ & $16(28.1)$ & $13(35.2)$ & & \\
\hline FELDA Neram 2 & $29(30.9)$ & $15(26.3)$ & $14(37.8)$ & & \\
\hline \multicolumn{6}{|l|}{ Gender } \\
\hline Male & $37(39.4)$ & $26(45.6)$ & $11(29.7)$ & & \\
\hline Female & $57(60.6)$ & $31(54.4)$ & $26(70.3)$ & & \\
\hline \multicolumn{6}{|l|}{ Ethnicity } \\
\hline Malay & $94(100)$ & $57(100)$ & $37(100)$ & & \\
\hline Age (years) & & & & $50.3(12.0)$ & $<0.05^{*}$ \\
\hline $19-30$ & $5(5.3)$ & $5(8.8)$ & - & & \\
\hline $31-40$ & $22(23.4)$ & $18(31.6)$ & $4(10.8)$ & & \\
\hline $41-50$ & $12(12.8)$ & $8(14.0)$ & $4(10.8)$ & & \\
\hline $51-60$ & $31(32.9)$ & $10(17.5)$ & $21(56.8)$ & & \\
\hline$>60$ & $24(25.6)$ & $16(28.1)$ & $8(21.6)$ & & \\
\hline \multicolumn{6}{|l|}{ Marital status } \\
\hline Single & $5(5.3)$ & $4(7.0)$ & $1(2.7)$ & & \\
\hline Married & $82(87.2)$ & $51(89.5)$ & $31(83.8)$ & & \\
\hline Widowed & $4(4.2)$ & $1(1.8)$ & $3(8.1)$ & & \\
\hline Divorced & $3(3.3)$ & $1(1.8)$ & $2(5.4)$ & & \\
\hline \multicolumn{6}{|l|}{ Educational level } \\
\hline No formal education & - & - & $1(2.7)$ & & \\
\hline Primary & - & - & $10(27)$ & & \\
\hline Secondary & - & - & $24(64.8)$ & & \\
\hline Tertiary & - & - & $2(5.4)$ & & \\
\hline \multicolumn{6}{|l|}{ Household income } \\
\hline$\leq \mathrm{RM} 1000$ & & - & - & $12(32.4)$ & \\
\hline$\geq \mathrm{RM} 1001$ & & - & - & $25(67.6)$ & \\
\hline \multicolumn{6}{|l|}{ Smoking status } \\
\hline Yes & & - & - & $4(10.8)$ & \\
\hline No & & - & - & $33(89.1)$ & \\
\hline \multicolumn{6}{|c|}{ Taking anti-hypertension medication } \\
\hline Yes & & - & - & $21(56.8)$ & \\
\hline No & & - & - & $16(43.2)$ & \\
\hline \multicolumn{6}{|l|}{ Practice a low salt diet } \\
\hline Yes & & - & - & $22(59.5)$ & \\
\hline No & & - & - & $15(40.5)$ & \\
\hline
\end{tabular}

*significant at $p<0.05$ using chi-square test.

The percentage of answers from hypertensive participants' answers towards the statement of KAP of salt intake is shown in Table 2. The level of KAP was categorized into poor, fair, and good. All of the participants in the hypertensive group $(100 \%)$ had good knowledge about salt intake. They agreed that a high salt diet can cause severe health problems and could lead to high blood pressure. However, only $62.2 \%$ agreed that lowering salt in their daily diet was very important while $35.1 \%$ and $2.7 \%$ choose that decreasing salt intake was somewhat important and not important at all, respectively. The level of attitude towards salt intake was high in the good level
(70.3\%), followed by fair attitude (27\%) and poor attitude $(2.7 \%)$, respectively. In addition, $78.4 \%$ of hypertensive participants agreed they consumed the right amount of salt. Meanwhile, practice towards salt intake was in the poor level (56.8\%), where $51.3 \%$ of them did not do anything to control their salt/ sodium intake. Besides, $91.9 \%$ of them never added salt to food at the table though $62.2 \%$ always added salt in their daily cooking. Lastly, for those who did something to control their salt intake, they were most likely not adding salt at the table (16.2\%).

Table 3 shows current blood pressure by gender grouping. Males had higher systolic blood pressure 
Table 2. KAP towards salt intake, $n=37$ (Hypertensive only)

\begin{tabular}{|c|c|c|c|c|}
\hline Variables & $\begin{array}{l}\text { Total } \\
n(\%)\end{array}$ & $\begin{array}{l}\text { Poor } \\
n(\%)\end{array}$ & $\begin{array}{l}\text { Fair } \\
n(\%)\end{array}$ & $\begin{array}{l}\text { Good } \\
n(\%)\end{array}$ \\
\hline KNOWLEDGE & & & & $37(100)$ \\
\hline $\begin{array}{l}\text { A high salt diet can cause health problem } \\
\text { Yes } \\
\text { No }\end{array}$ & $37(100)$ & & & \\
\hline $\begin{array}{l}\text { A high salt diet can cause hypertension } \\
\text { Yes } \\
\text { No }\end{array}$ & $37(100)$ & & & \\
\hline ATTITUDE & & $1(2.7)$ & $10(27)$ & $26(70.3)$ \\
\hline $\begin{array}{l}\text { How important to you is lowering salt in your } \\
\text { Very important } \\
\text { Somewhat important } \\
\text { Not important }\end{array}$ & $\begin{aligned} 23 & (62.2) \\
13 & (35.1) \\
1 & (2.7)\end{aligned}$ & & & \\
\hline $\begin{array}{l}\text { How much salt do you think you consume } \\
\text { Too little } \\
\text { Right amount } \\
\text { Too much }\end{array}$ & $\begin{array}{c}7(18.9) \\
29(78.4) \\
1(2.7)\end{array}$ & & & \\
\hline PRACTICE & & $21(56.8)$ & $14(37.8)$ & $2(5.4)$ \\
\hline $\begin{array}{l}\text { In the food you eat at home, salt is added to } \mathrm{C} \\
\text { Never } \\
\text { Rarely } \\
\text { Sometimes } \\
\text { Often } \\
\text { Always }\end{array}$ & $\begin{aligned} 1 & (2.7) \\
1 & (2.7) \\
12 & (32.4) \\
23 & (62.2)\end{aligned}$ & & & \\
\hline $\begin{array}{l}\text { Do you add salt to food at the table } \\
\text { Never } \\
\text { Rarely } \\
\text { Sometimes } \\
\text { Often } \\
\text { Always }\end{array}$ & $\begin{aligned} 34 & (91.9) \\
1 & (2.7) \\
& \\
1 & (2.7) \\
1 & (2.7)\end{aligned}$ & & & \\
\hline $\begin{array}{l}\text { Take regular action to control salt intake } \\
\text { Yes } \\
\text { No }\end{array}$ & $\begin{array}{l}18(48.6) \\
19(51.3)\end{array}$ & & & \\
\hline $\begin{array}{l}\text { If yes, what do you do? } \\
\text { Avoid/ minimize processed foods } \\
\text { Look at the salt labels } \\
\text { Do not add salt to the table } \\
\text { Buy low salt alternatives } \\
\text { Do not add salt when cooking } \\
\text { Use spices other than salt when cooking }\end{array}$ & $\begin{array}{l}5(13.5) \\
2(5.4) \\
6(16.2) \\
5(13.5) \\
9(24.3) \\
1(2.7)\end{array}$ & & & \\
\hline
\end{tabular}

Table 3. Current blood pressure, $n=94$

\begin{tabular}{lccc}
\hline Variables & Male $n(\%)$ & Female $n(\%)$ & $P$-value \\
\hline $\begin{array}{l}\text { Systolic Blood Pressure } \\
\quad \text { High }\end{array}$ & $15(40.5)$ & $19(33.3)$ & $>0.05$ \\
$\quad$ Normal & $22(59.5)$ & $38(66.7)$ & \\
$\begin{array}{l}\text { Diastolic Blood Pressure } \\
\quad \text { High }\end{array}$ & $14(37.8)$ & $8(14.0)$ & $<0.05^{*}$ \\
$\quad$ Normal & $23(62.2)$ & $49(86.0)$ & \\
Blood Pressure Categorical & & & \\
$\quad$ High & $18(48.6)$ & $21(36.8)$ & \\
$\quad$ Normal & $19(51.4)$ & $36(63.2)$ & \\
\hline
\end{tabular}

*significant at $p<0.05$ using chi-square test. 
Table 4. Nutritional status and current blood pressure reading

\begin{tabular}{|c|c|c|c|c|}
\hline Variables & $\begin{array}{c}\text { Non-Hypertensive } \\
n=57 \\
(n, \%)\end{array}$ & $\begin{array}{c}\text { Hypertensive } \\
n=37 \\
(n, \%)\end{array}$ & Mean (SD) & $P$-value \\
\hline $\begin{array}{l}\text { Anthropometry BMI }\left(\mathrm{kg} / \mathrm{m}^{2}\right) \\
\text { Normal }(18.5-22.9) \\
\text { Overweight }(23-24.9) \\
\text { Obese I }(25-29.9) \\
\text { Obese II }(\geq 30)\end{array}$ & $\begin{array}{l}11(19.3) \\
12(21.1) \\
19(33.3) \\
15(26.3)\end{array}$ & $\begin{aligned} 1 & (2.7) \\
3 & (8.1) \\
14 & (37.8) \\
19 & (51.4)\end{aligned}$ & $28.5(5.1)$ & $<0.05^{*}$ \\
\hline $\begin{array}{l}\text { Waist circumference }(\mathrm{cm}) \\
\text { Low risk } \\
\text { High risk }\end{array}$ & $\begin{array}{ll}20 & (35.1) \\
37 & (64.9)\end{array}$ & $\begin{array}{c}5(13.5) \\
32(86.5)\end{array}$ & $92.8(12.0)$ & $<0.05^{*}$ \\
\hline $\begin{array}{l}\text { Waist to Hip Ratio } \\
\text { Low risk } \\
\text { High risk }\end{array}$ & $\begin{array}{l}22(38.6) \\
35(61.4)\end{array}$ & $\begin{array}{c}8(21.6) \\
29(78.4)\end{array}$ & $0.90(0.1)$ & $>0.05$ \\
\hline \multicolumn{5}{|l|}{ Clinical } \\
\hline $\begin{array}{l}\text { BP }(\mathrm{mmHg}) \\
\text { Normal } \\
\text { High }\end{array}$ & $\begin{array}{l}37(64.9) \\
20(35.1)\end{array}$ & $\begin{array}{l}18(48.6) \\
19(51.4)\end{array}$ & & \\
\hline $\begin{array}{l}\text { SBP }(\mathrm{mmHg}) \\
\text { Normal } \\
\text { High }\end{array}$ & $\begin{array}{l}41(71.9) \\
16(28.1)\end{array}$ & $\begin{array}{l}19(51.4) \\
18(48.6)\end{array}$ & $134.4(17.2)$ & $>0.05$ \\
\hline $\begin{array}{l}\text { DBP }(\mathrm{mmHg}) \\
\quad \text { Normal } \\
\text { High }\end{array}$ & $\begin{array}{l}45(78.9) \\
12(21.1)\end{array}$ & $\begin{array}{l}27(73.0) \\
10(27.0)\end{array}$ & $82.3(12.6)$ & $>0.05$ \\
\hline
\end{tabular}

BP: blood pressure; SBP: systolic blood pressure; DBP: diastolic blood pressure. *significant at $p<0.05$ using chi-square test.

(SBP), (40.5\%) compared to females $(33.3 \%)$. Meanwhile, most of the participants both males and females had normal diastolic blood pressure (DBP) with $62.2 \%$ and $86 \%$, respectively. There was a significant association between gender and DBP ( $p=0.003$ ). Among the participants, 55.3\% had normal current blood pressure reading whereas $44.7 \%$ had high current blood pressure reading. Twenty-one out of 57 females had been categorized as high current blood pressure reading while 18 out of 37 males had high current blood pressure reading. The prevalence of hypertension among adults in the three FELDA areas was $39.4 \%$.

The mean BMI of the participants was 28.5 (5.1) $\mathrm{kg} / \mathrm{m}^{2}$, as shown in Table 4 . According to the Asian-specific BMI cut-off points, most of the participants were obese $(71.3 \%)$, whereas $12.8 \%$ and $16 \%$ were normal and overweight, respectively. In the hypertensive group, 33 out of 37 participants were obese. By waist circumference, most of the participants $(76.6 \%)$ were categorized under the highrisk group based on the cut-off point. The majority, in both the non-hypertensive and hypertensive groups, were considered high risks with $64.9 \%$ and $86.5 \%$, respectively. BMI and waist circumference had a significant association with hypertension. Meanwhile, for WHR, most of the participants (68.1\%) were classified in the high-risk group. More than half
(78.4\%) of the hypertensive participants were categorized in the high-risk group according to WHR.

\section{DISCUSSION}

This study revealed a high prevalence of hypertension in the FELDA areas (39.4\%). The FELDA areas in Terengganu are considered as one of the rural areas. According to Abdul-Razak et al. (2016), the prevalence of undiagnosed hypertension and hypertension were both higher in the rural areas with $20.7 \%$ and $51.2 \%$, respectively. The prevalence in this study was higher compared to the previous survey, which was conducted in 2015, where Terengganu's prevalence was $26.9 \%$ (National Health Morbidity Survey, 2015). This increasing pattern of prevalence was common in other countries as well (Picon et al., 2012).

Gender difference in hypertension was common due to biological factors such as sex hormone and chromosomal differences (Everett \& Zajacova, 2015). Meanwhile, according to Mahadir et al. (2019), the prevalence of prehypertension was higher among men $(52.6 \%)$ than women $(38.1 \%)$. There was significant mean age in hypertension. The results were similar in other studies as well (Mafauzy et al., 2003; Kishore et al., 2016; Agyei-Baffour et al., 2018; 
Peltzer, 2018). Hypertension was increasing with age in both males and females due to the changes in arterial and arteriolar stiffness (Pinto, 2007). A study conducted in Singapore showed that Malay ethnicity, aging, and low educational levels were factors that were significantly associated with hypertension (Liew et al., 2019). As more than half of the participants in the hypertensive group were taking anti-hypertension medication and practicing a low salt diet, it showed that most of them were taking good care of their health.

In general, knowledge and education are two things that will come along because there is no knowledge without education. As this study showed that most of the participants had a good understanding knowledge of salt intake, it might be due to most of the participants had secondary education. According to Mahat et al. (2017), knowledge of attitude towards salt intake was significantly associated with a 24-hr urinary sodium excretion among healthcare staff. In a study carried out among healthy Jordanian adults, only $29 \%$ of the participants agreed that reducing salt intake was significant to health, and only $1 \%$ of the participants regularly checked the food labels for salt content (Alawwa et al., 2018). The result was similar to this study since only $5.4 \%$ glanced at the salt labels. More than half of the participants in this study claimed they consumed the right amount of salt, and this was similar to the previous research study as well.

According to a study carried out among Australians, the majority of the participants (81\%) associated a high salt diet with rising blood pressure, and $50 \%$ of the participants claimed that they consumed the right amount of salt. However, only $18 \%$ recognized that the recommended dietary salt intake is $6 \mathrm{~g}$ per day (Land et al., 2014). Practicing a low salt diet was higher at an unsatisfactory level because changing the salty preference and appetite for current salt intake in a particular population might lead to loss of palatability and unacceptable for individuals' taste preferences (Bi et al., 2014). Besides, other studies indicated that the participants claimed less sodium intake made them feel less in physical strength (Zhang et al., 2013). This study found that majority of the participants did not use spice as a salt alternative. This might be due to their unfamiliarity with the cooking skills by using seasoning spices and other natural flavors as enhancers to the food (Ruusunen et al., 2003).

Next, the BMI showed that both groups, the non-hypertensive and hypertensive groups had higher participants in the obese I and obese II category compared to the standard weight and overweight. It was not shocking news since Malaysia has the highest prevalence of obesity among adults in the South-East Asian countries, followed by Brunei and Thailand with 15.6\%, 14.1\%, and $10.0 \%$, respectively. As obesity was one of the most significant factors in hypertension, it was crucial to tackle the anthropometry status in preventing hypertension (Lee et al., 2015). The BMI did not show any indication of the distribution in the body, thus by measuring waist circumference, the researcher could determine the fat distribution in the body. Higher fat in the body will act as resistance to blood flow, thus lead to an increase in blood pressure (Lee \& Kwon, 2019). The waist circumference for the hypertensive group participants was classified as high risk. The previous study showed that waist circumference is the strongest independent predictor for blood pressure and central adiposity was associated with a higher prevalence of elevated blood pressure (Siani et al., 2002).

More than half of the hypertensive participants had higher WHR. Even though waist circumference was a notable marker for abdominal obesity, WHR was also a prominent marker in hypertension. According to Zhao et al. (2000), the average blood pressure and the prevalence of hypertension stopped increasing when the WHR value decreased. The WHR of most participants showed a higher value than 0.80 and 0.90 in females and males, respectively. Besides, WHR offered additional information in the prediction of hypertension among adults (Feldstein et al., 2005).

However, this study has several limitations. Firstly, the comparison between hypertensive and non-hypertensive groups may differ from other studies due to different methodologies and criteria used in the study. Secondly, the information regarding the diagnosis of hypertension and medication of hypertension may be bias due to the recall method. However, proper training had been done before conducting the survey and its procedures to minimize the potential bias. Thirdly, the data should be cautiously interpreted due to the small sample size since this study did not achieve the minimum sample size needed. The population for this study also had more females than males.

\section{CONCLUSION}

In conclusion, this study showed a general KAP towards salt intake results among the rural population. The outcomes of this study could be applied to stop the increase in the prevalence among the rural community. Besides, this study could also trigger an alarm about obesity in our population. Obesity should not be underestimated as it was one of the strongest factors of hypertension. Findings from this study emphasized the urgency to tackle the rising hypertension prevalence and the almost inevitable emerging epidemic of cardiovascular 
diseases in Malaysia. The KAP could be a great measure to run the awareness campaign for the rural communities to educate them on the benefits of reducing salt intake. Lastly, the findings of this study can also be used as a reference for other studies involving rural or plantation area populations.

\section{ACKNOWLEDGEMENT}

We would like to thank those who were involved direct or indirectly in this study.

\section{REFERENCES}

Abdul-Razak, S., Daher, A.M., Ramli, A.S., Ariffin, F., Mazapuspavina, M.Y., Ambigga, K.S. \& Yusoff, K. 2016. Prevalence, awareness, treatment, control and socio demographic determinants of hypertension in Malaysian adults. BMC Public Health, 16: 1-10.

Agyei-Baffour, P., Tetteh, G., Quansah, D.Y. \& Boateng, D. 2018. Prevalence and knowledge of hypertension among people living in rural communities in Ghana: a mixed method study. African Health Sciences, 18(4): 931-941.

Alawwa, I. 2018. Dietary salt consumption and the knowledge, attitudes and behavior of healthy adults/ : a cross-sectional study from Jordan. Libyan Journal of Medicine, 13(1).

Azahari, S., Badari, Z., Arcot, J. \& Sulaiman, N. 2013. Food consumption patterns of lower-income households in rural areas of Peninsular Malaysia. Jurnal Pengguna Malaysia, 21: 122-141

Bi, Z., Liang, X., Xu, A., Wang, L., Shi, X., Zhao, W. \& Wang, Y. 2014. Hypertension prevalence, awareness, treatment, and control and sodium intake in Shandong Province, China: Baseline results from Shandong - Ministry of Health Action on salt reduction and hypertension sample size and sampling frame. Preventing Chronic Disease, 11: 1-15.

Bibbins-Domingo, K., Chertow, G.M., Coxson, P.G., Moran, A., Lightwood, J.M., Pletcher, M.J. \& Goldman, L. 2010. Projected effect of dietary salt reductions on future cardiovascular disease. Obstetrical and Gynecological Survey, 65(7): 441-442.

Bhana, N., Utter, J., Eyles, H. \& Utter, J. 2018. Knowledge, attitudes and behaviours related to dietary salt intake in high-income countries: A systematic review. Current Nutrition Reports, 7(4): 183-197.
Chen, J., Liao, Y., Li, Z., Tian, Y., Yang, S., He, C. \& Sun, X. 2013. Determinants of salt-restrictionspoon using behavior in China: Application of the health belief model. Public Library of Science, 8(12): 1-9.

Everett, B. \& Zajacova, A. 2015. Gender differences in hypertension and hypertension awareness among young adults. Biodemography and Social Biology, 61(1): 1-17.

Eyles, H., McLean, R., Neal, B., Doughty, R.N., Jiang, Y. \& Mhurchu, C.N. 2014. Using mobile technology to support lower-salt food choices for people with cardiovascular disease: protocol for the SaltSwitch randomized controlled trial. BMC Public Health, 14: 1-8.

Federal Land Development Authority (FELDA). 2019. About FELDA. URL https://felda.gov.my/en/ public/felda/about-felda (accessed 10.25 20).

Feldstein, C.A., Akopian, M., Olivieri, A.O., Kramer, A.P., Nasi, M. \& Garrido, D. 2005. A comparison of body mass index and waist-to-hip ratio as indicators of hypertension risk in an urban Argentine population: a hospital-based study. Nutrition, Metabolism and Cardiovascular Diseases, 15(4): 310-315.

Grimes, C.A., Riddell, L. \& Nowson, C.A. 2010. The use of table and cooking salt in a sample of Australian adults. Asia Pacific Journal of Clinical Nutrition, 19(2): 256-260.

Institute for Public Health. 2014. National Health and Morbidity Survey 2014: Malaysian Adult Nutrition Survey (MANS) Vol. II. URL http:// iku.moh.gov.my/images/IKU/Document/ REPORT/NHMS2014-MANS-VOLUME-2SurveyFindings.pdf (accessed 10.20.20).

Kishore, J., Gupta, N., Kohli, C. \& Kumar, N. 2016. Prevalence of hypertension and determination of its risk factors in rural Delhi. International Journal of Hypertension, 2016.

Land, M., Webster, J., Christoforou, A., Johnson, C., Trevena, H., Hodgins, F. \& Neal, B. 2014. The association of knowledge, attitudes and behaviours related to salt with 24-hour urinary sodium excretion. International Journal of Behavioral Nutrition and Physical Activity, 11: 1-8.

Lee, J.W., Lim, N.K., Baek, T.H., Park, S.H. \& Park, H.Y. 2015. Anthropometric indices as predictors of hypertension among men and women aged 40-69 years in the Korean population: The Korean Genome and Epidemiology Study. BMC Public Health, 15(1): 1-7. 
Lee, S.B., Cho, A.R., Kwon, Y.J. \& Jung, D.H. 2019. Body fat change and 8 year incidence of hypertension: The Korean Genome and Epidemiology Study. The Journal of Clinical Hypertension, 21(12): 1849-1857.

Liew, S.J., Lee, J.T., Tan, C.S., Koh, C.H.G., Van Dam, R. \& Müller-Riemenschneider, F. 2019. Sociodemographic factors in relation to hypertension prevalence, awareness, treatment and control in a multi-ethnic Asian population: A crosssectional study. BMJ Open, 9(5): e025869.

Mafauzy, M., Mokhtar, N. \& Wan Mohamad, W.B. 2003. Hypertension and associated cardiovascular risk factors in Kelantan. Medical Journal of Malaysia, 58(4): 556-564.

Mahadir, B., Id, N., Fadhli, M., Yusoff, M., Id, S.A., Sahril, N. \& Aris, T. 2019. Factors associated with the severity of hypertension among Malaysian adults. PLoS One, 14(1): 1-16.

Mahat, D., Isa, Z., Tamil, A.M., Mahmood, M.I. \& Othman, F. 2017. The association of knowledge , attitude and practice with 24 hours urinary sodium excretion among Malay healthcare staff. International Journal of Public Health Research, 7(2): 860-870.

Peltzer, K. 2018. The prevalence and social determinants of hypertension among adults in Indonesia/ : A cross-sectional population-based national survey. International Journal of Hypertension, 2018: 5610725.

Picon, R.V., Fuchs, F.D., Moreira, L.B., Riegel, G. \& Fuchs, S.C. 2012. Trends in prevalence of hypertension in Brazil: a systematic review with meta-analysis. PLoS One, 7(10): e48255.

Pinto, E. 2007. Blood pressure and ageing. Postgraduate Medical Journal, 83(976): 109-114.

Martin, Thomas, P., Fischer. \& Anastasia, N. 2012. Sodium, potassium, and high blood pressure. ACSM's Health \& Fitness Journal, 16(3): 13-21.

Rashidah, A., Yeo, P.S., Noor Ani, A., Muhammad Fadhli, M.Y., Tahir, A., Feisul Idzwan, M. \& Madihah, M. 2014. Sodium intake among normotensive health staff assessed by 24 -hour urinary excretion: A cross-sectional study. Malaysian Journal of Nutrition, 20(3): 317-326.
Ruusunen, M., Vainionpää, J., Puolanne, E., Lyly, M., Lähteenmäki, L., Niemistö, M. \& Ahvenainen, R. 2003. Physical and sensory properties of low-salt phosphate-free frankfurters composed with various ingredients. Meat Science, 63(1): 9-16.

Shahar, S., Vanoh, D., Fitri, A., Ludin, M., Kaur, D., Singh, A. \& Hamid, T.A. 2019. Factors associated with poor socioeconomic status among Malaysian older adults: An analysis according to urban and rural settings, BMC Public Health, 19(Suppl 4): 1-12.

Siani, A., Cappuccio, F.P., Barba, G., Trevisan, M., Farinaro, E., Iacone, R. \& Strazzullo, P. 2002. The relationship of waist circumference to blood pressure: The Olivetti Heart Study. American Journal of Hypertension, 15(9): 780-786.

Spronk, I., Kullen, C., Burdon, C. \& Connor, H.O. 2019. Relationship between nutrition knowledge and dietary intake. British Journal of Nutrition, 111(10): 1713-1726.

Wellman, R.J., Vaughn, J.A., Sylvestre, M.P., O’Loughlin, E.K., Dugas, E.N. \& O’Loughlin, J.L. 2016. Relationships between current and past binge drinking and systolic blood pressure in young adults. Journal of Adolescent Health, 58(3): 352-357.

WHO. 2012. Guideline: sodium intake for adults and children. Geneva: World Health Organization. URL http://www.who.int/nutrition/publications/ guidelines/sodium_intake/en/(accessed 9.30.20).

WHO. 2017. Cardiovascular Disease. URL https://www.who.int/news-room/fact-sheets/ detail/cardiovascular-diseases-(cvds) (accessed 9.28.20).

Zhang, J., Xu, A., Ma, J., Shi, X., Guo, X., Engelgau, M. \& Liang, X. 2013. Dietary sodium intake: Knowledge, attitudes and practices in Shandong Province, China, 2011. PLoS One, 8(3): 1-7.

Zhao, W., Xu, H., Zhang, X., Wang, J., Yin, C., Li, M. \& Chen, J. 2000. The association of BMI and WHR on blood pressure levels and prevalence of hypertension in middle-aged and elderly people in rural China. Biomedical and Environmental Sciences, 13(3): 189-197. 
